\title{
Effects on pre- and posttransplant pulmonary hemodynamics in patients with continuous-flow left ventricular assist devices
}

\author{
Ranjit John, MD, ${ }^{\mathrm{a}}$ Kenneth Liao, MD, ${ }^{\mathrm{a}}$ Forum Kamdar, MD, ${ }^{\mathrm{b}}$ Peter Eckman, MD, ${ }^{\mathrm{b}}$ \\ Andrew Boyle, $\mathrm{MD},{ }^{\mathrm{b}}$ and Monica Colvin-Adams, $\mathrm{MD}^{\mathrm{b}}$
}

\begin{abstract}
Objective: Pulsatile left ventricular assist devices have been shown to effectively reduce pulmonary hypertension in patients with end-stage heart failure. However, it remains to be seen whether newer continuous-flow left ventricular assist devices have a similar effect on pulmonary hypertension. The objective of this study was to determine whether the HeartMate II (Thoratec Corp, Pleasanton, Calif), a continuous-flow left ventricular assist device, is effective in improving pulmonary hemodynamics in the period after left ventricular assist device support and posttransplant.
\end{abstract}

\begin{abstract}
Methods: Fifty patients with end-stage heart failure underwent HeartMate II left ventricular assist device placement as a bridge to transplant. We evaluated their pulmonary hemodynamics with right-sided heart catheterization at baseline, after left ventricular assist device placement, and after heart transplant.
\end{abstract}

Results: The mean age of patients was $53.7 \pm 13.5$ years. Ischemic etiology was present in $60 \%$ of the patients. After left ventricular assist device placement (mean duration, $135 \pm 60$ days), mean systolic and diastolic pulmonary artery pressures decreased significantly from a baseline of $55.2 \pm 13.4 \mathrm{~mm} \mathrm{Hg}$ and $27.3 \pm 6.8 \mathrm{~mm} \mathrm{Hg}$, respectively, to $35.9 \pm 10.8 \mathrm{~mm} \mathrm{Hg}$ and $15.8 \pm 6.5 \mathrm{~mm} \mathrm{Hg}$, respectively $(P<.001)$. Similarly, mean pulmonary vascular resistance decreased significantly from a baseline of $3.6 \pm 1.9$ Woods units to $2.1 \pm 0.8$ Woods units $(P<.001)$. Posttransplant pulmonary hemodynamics also remained within normal limits, even in patients with previously severe pulmonary hypertension.

Conclusion: Continuous-flow left ventricular assist devices effectively improve pulmonary hemodynamics associated with end-stage heart failure. Moreover, pulmonary hemodynamics remain within normal limits in the posttransplant period, even in patients with severe pulmonary hypertension. Therefore, adequate left ventricular decompression achieved with newer left ventricular assist devices can reverse significant pulmonary hypertension in patients with end-stage heart failure, making them eligible for cardiac transplantation. (J Thorac Cardiovasc Surg 2010;140:447-52)

Orthotopic heart transplantation is an established treatment modality for patients with end-stage heart failure. An increasing number of patients are being successfully bridged to a heart transplant by a left ventricular assist device (LVAD). ${ }^{1}$ Most patients who have undergone LVAD placement as a bridge to transplant (BTT) in the United States have historically been supported by pulsatile, volumedisplacement devices, such as the HeartMate XVE (Thoratec Corp, Pleasanton, Calif). ${ }^{2}$ These devices provide excellent hemodynamic support and improve patient survival, yet they have significant constraints, including the need for extensive surgical dissection, a large body size requirement,

\footnotetext{
From the Division of Cardiothoracic Surgery, ${ }^{\mathrm{a}}$ Department of Surgery and Division of Cardiology, ${ }^{\mathrm{b}}$ University of Minnesota, Minneapolis, Minn. Disclosures: None.

Received for publication Nov 30, 2009; revisions received Feb 8, 2010; accepted for publication March 9, 2010; available ahead of print May 3, 2010.

Address for reprints: Ranjit John, MD, Division of Cardiothoracic Surgery, University

of Minnesota, Minneapolis, MN 55455 (E-mail: johnx008@umn.edu).

$0022-5223 / \$ 36.00$

Copyright (c) 2010 by The American Association for Thoracic Surgery

doi:10.1016/j.jtcvs.2010.03.006
}

a large-diameter percutaneous lead, and audible pump operation. Even more important, their long-term mechanical durability is limited, frequently requiring reoperations for device exchange. The newer HeartMate II LVAD, which incorporates continuous flow, rotary pump technology, represents the next generation of devices. The focus of new pumps is enhanced durability and quality of life for extended periods of circulatory support. A major advantage of these new pumps is their small size, thereby extending therapy to underserved patient populations, including women and even some children. ${ }^{3,4}$

Despite several advances in the field of heart transplantation, the presence of pulmonary hypertension $(\mathrm{PH})$ remains a risk factor for adverse outcomes posttransplant, primarily related to acute donor right-sided heart failure. ${ }^{5-7}$ In some of these patients, severe $\mathrm{PH}$ is reversible by pharmacologic means; however, there are limitations of pharmacologic therapies, such as preexisting systemic hypotension. By unloading the left ventricle, LVADs can reduce elevated pulmonary artery pressures. Pulsatile LVADs as a BTT have been proven to be beneficial in reversing $\mathrm{PH}$ in patients, but published data on the efficacy of lowering $\mathrm{PH}$ 


$$
\begin{aligned}
& \text { Abbreviations and Acronyms } \\
& \text { BTT }=\text { bridge to transplant } \\
& \text { DPAP }=\text { diastolic pulmonary artery pressure } \\
& \text { LVAD }=\text { left ventricular assist device } \\
& \text { PH }=\text { pulmonary hypertension } \\
& \text { PVR }=\text { pulmonary vascular resistance } \\
& \text { SPAP }=\text { systolic pulmonary artery pressure } \\
& \text { TPG }=\text { transpulmonary gradient }
\end{aligned}
$$

using continuous-flow devices are limited. Previous studies showed that axial flow devices provide similar degrees of pressure unloading, but less volume unloading, of the left ventricle compared with pulsatile devices. Such findings may have significant implications for patients with severe $\mathrm{PH}$ that is medically unresponsive. Also unknown is the degree of PH that may exist or recur after heart transplantation and LVAD removal. We report our initial experience, based on a prospective, single-center study, regarding the efficacy of the HeartMate II LVAD to effectively improve pulmonary hemodynamics in the period after LVAD support and in the posttransplant period. Our study included $50 \mathrm{pa}-$ tients with a BTT and end-stage heart failure at the University of Minnesota Medical Center.

\section{MATERIALS AND METHODS \\ Patients}

From October 1, 2005, to January 2009, a total of 70 patients (mean age, $57.24 \pm 14.2$ years) underwent HeartMate II placement at the University of Minnesota Medical Center (BTT in 50 patients, destination therapy in $10 \mathrm{pa}-$ tients, and LVAD exchange for a failed XVE model in 10 patients). The total duration of LVAD support was 352.1 patient-months (mean duration, $7.8 \pm 5.4$ months).

This study focuses on the 50 patients with a BTT who underwent HeartMate II placement. Patients with end-stage heart failure who were on our transplant waiting list were eligible for study enrollment. The protocol for the study was approved by the Food and Drug Administration and the institutional review board at the University of Minnesota Medical Center. Patient consent for data collection and reporting was obtained by a standard informed consent process.

\section{HeartMate II}

The HeartMate II consists of an internal blood pump with a percutaneous lead that connects the pump to an external system driver and power source. The pump has an implant volume of $63 \mathrm{~mL}$ and generates up to $10 \mathrm{~L} / \mathrm{min}$ of flow at a mean pressure of $100 \mathrm{~mm} \mathrm{Hg}$. The details of the HeartMate II function and the implant technique have been described. ${ }^{5}$

\section{Hemodynamic Evaluation}

We evaluated patient hemodynamics with right-sided heart catheterization at baseline, 3 months after LVAD, and 1 month after transplant. By using the Swan-Ganz catheter (Baxter Healthcare, Irvine, Calif), we obtained measurements while the patient was at rest in a supine position. We defined severe PH by pulmonary vascular resistance (PVR) 4 or more Woods units or by transpulmonary gradient (TPG) $15 \mathrm{~mm} \mathrm{Hg}$ or greater.

\section{Device Management}

Device management reflects our local practice at the University of Minnesota. We performed all measurements with the device on fixed-rate speed. The rpm rate of the HeartMate II was set to provide adequate cardiac output and achieve optimal left ventricular decompression while maintaining a pulsatility index greater than 3.5 to 4 . In addition, we usually adjusted the fixed-rate speed of the HeartMate II to maximize left ventricular decompression and to improve cardiac output, simultaneously attempting to allow for at least a 1:3 ratio of aortic valve opening. We optimized the speed both hemodynamically and echocardiographically at the time of LVAD placement and if clinical events (eg, new symptoms or suction events) warranted further adjustment.

All patients were on standard heart failure therapy, including antiarrhythmic therapy as per our usual practice. Anticoagulation involved a combination of warfarin and aspirin. Defibrillator or biventricular pacing settings were not changed after LVAD placement. All patients underwent a standard postoperative rehabilitation program.

\section{Data Collection}

With signed informed patient consent forms and study enrollment, we collected baseline and follow-up data, including patient characteristics, hemodynamic parameters, blood chemistry analyses, hematologic findings, neurologic status, and concomitant medications. After patients were discharged from the hospital, they returned to the University of Minnesota Medical Center for follow-up, device review, and general status assessment.

\section{Statistical Analysis}

To analyze differences between hemodynamic measurements before and after LVAD placement, we used an independent-samples test. To compare categoric variables, we used the chi-square or Fisher's exact test. To compare continuous variables, we used a Student $t$ test if normally distributed; if not, a Wilcoxon rank-sum test was used. Values are reported as mean \pm standard deviation. For all data, we used the SAS System software version 9.0 (SAS Institute, Inc, Cary, NC).

\section{RESULTS \\ Patient Characteristics}

The mean age of the 50 patients with a BTT was $53.7 \pm$ 13.6 years (range, $23-71$ years). There were 34 male and 16 female patients. Among the patients with a BTT, the cause of heart failure was ischemic in $60 \%(\mathrm{n}=30)$ and idiopathic in $34 \%(n=17)$; 1 patient had postpartum cardiomyopathy, and 2 patients had congenital heart disease. The overall mean duration of HeartMate II support in the BTT group was $281 \pm 249$ days. The characteristics at baseline for the patients with a HeartMate II BTT are summarized in Table 1.

\section{Hemodynamic Data}

Hemodynamic data at baseline (50 patients with BTT) are shown in Table 2.

\section{Effect on Pulmonary Hemodynamics}

After LVAD placement (mean duration, $135 \pm 60$ days) in the 50 patients with a BTT, the mean systolic pulmonary artery pressure (SPAP) and diastolic pulmonary artery pressure (DPAP) decreased significantly from a baseline of $55.2 \pm 13.4 \mathrm{~mm} \mathrm{Hg}$ and $27.3 \pm 6.8 \mathrm{~mm} \mathrm{Hg}$, respectively, 
TABLE 1. Characteristics of patients at baseline $(n=50)$

\begin{tabular}{lc}
\hline Mean age, $y$ & $53.7 \pm 13.6$ (range, 23-71) \\
Gender ratio (M:F) & $34: 16$ \\
Cause of heart failure & \\
Ischemic & $30(60 \%)$ \\
Idiopathic & $17(34 \%)$ \\
Congenital & $2(4 \%)$ \\
Postpartum cardiomyopathy & $1(2 \%)$ \\
Duration of LVAD support, d & $281 \pm 249$ (range, 10-906) \\
\hline
\end{tabular}

$L V A D$, Left ventricular assist device.

to $35.9 \pm 10.8 \mathrm{~mm} \mathrm{Hg}$ and $15.8 \pm 6.5 \mathrm{~mm} \mathrm{Hg}$, respectively $(P<.001)$. Similarly, their mean PVR decreased significantly from a baseline of $3.6 \pm 1.9$ Woods units to $2.10 \pm 0.8$ Woods units $(P<.001)$. Their mean TPG also declined significantly from a baseline of $12.6 \pm 5.3 \mathrm{~mm} \mathrm{Hg}$ to $9.4 \pm 3.0 \mathrm{~mm} \mathrm{Hg}$; $P=.001$ (Table 2).

\section{Severe Pulmonary Hypertension}

Severe PH (ie, medically unresponsive) was identified in 18 patients (mean PVR, $5.2 \pm 1.7$ Woods units; mean TPG, $17.5 \pm 4.9 \mathrm{~mm} \mathrm{Hg}$ ). After LVAD support (mean duration, $170 \pm 111$ days), all measurements of severe $\mathrm{PH}$, including PVR, TPG, SPAP, and DPAP, decreased significantly. Of the 18 patients with severe $\mathrm{PH}, 4$ required advanced medical therapy (phosphodiesterase type 5 inhibitors) in addition to LVAD support and standard vasodilatory therapy. We noted no difference in the trend of change in pulmonary hemodynamics compared with the remaining 32 patients with a BTT without severe PH (Table 3, Figure 1).

\section{Effect on Mitral Regurgitation}

Mitral regurgitation was graded as follows: $0=$ normal to trace; $1=$ mild; $2=$ moderate; $3=$ moderately severe; and $4=$ severe mitral regurgitation. There was a significant reduction after LVAD placement in the severity of mitral regurgitation in patients with non-severe $\mathrm{PH}$ (baseline $1.96 \pm 1.3$

TABLE 2. Patient hemodynamics $(n=50)$

\begin{tabular}{lcc}
\hline \multicolumn{1}{c}{ Mean \pm SD } & Baseline & Post-LVAD \\
\hline Mean follow-up, d & 0 & $135 \pm 60$ \\
SPAP, mm Hg* & $55.2 \pm 13.4$ & $35.9 \pm 10.8$ \\
DPAP, mm Hg* & $27.3 \pm 6.8$ & $15.8 \pm 6.5$ \\
Mean PAP, mm Hg* & $36.7 \pm 8.8$ & $22.5 \pm 7.5$ \\
Right atrial mean, mm Hg* & $13.0 \pm 5.6$ & $7.0 \pm 5.6$ \\
PCWP, mm Hg* & $24.0 \pm 5.9$ & $13.1 \pm 6.7$ \\
PVR, Woods units* & $3.6 \pm 1.9$ & $2.10 \pm 0.83$ \\
TPG, mm Hg* & $12.6 \pm 5.3$ & $9.43 \pm 3.0$ \\
CO, L/min* & $3.9 \pm 1.3$ & $4.8 \pm 1.3$ \\
CI* & $2.0 \pm 0.5$ & $2.4 \pm 0.5$ \\
\hline SD, Standard
\end{tabular}

$S D$, Standard deviation; $L V A D$, left ventricular assist device; $S P A P$, systolic pulmonary artery pressure; $D P A P$, diastolic pulmonary artery pressure; $P A P$, pulmonary artery pressure; $P C W P$, pulmonary capillary wedge pressure; $P V R$, pulmonary vascular resistance; $T P G$, transpulmonary gradient; $C O$, cardiac output; $C I$, cardiac index. * Statistically significant, $P<.05$.
TABLE 3. Pulmonary hemodynamics of patients with $(n=18)$ and without $(n=32)$ severe pulmonary hypertension

\begin{tabular}{lccc}
\hline Severe PH $(\mathbf{N}=\mathbf{1 8})$ & Baseline & Post-VAD & $\boldsymbol{P}$ value \\
\hline SPAP $(\mathrm{mm} \mathrm{Hg})^{*}$ & $63.3 \pm 12.5$ & $37.0 \pm 11.1$ & $<.001$ \\
DPAP (mm Hg) & $30.8 \pm 5.3$ & $15.2 \pm 7.1$ & $<.001$ \\
PVR (Woods Units)* & $5.2 \pm 1.7$ & $2.6 \pm 0.9$ & $<.001$ \\
TPG (mm Hg)* & $17.5 \pm 4.0$ & $10.7 \pm 3.3$ & $<.001$ \\
Normal PH (n=32) & & & \\
SPAP (mm Hg)* & $49.5 \pm 10.7$ & $35.7 \pm 10.7$ & $<.001$ \\
DPAP (mm Hg)* & $24.6 \pm 6.4$ & $16.6 \pm 6.1$ & $<.001$ \\
PVR (Woods Units) & $2.4 \pm 0.9$ & $1.8 \pm 0.7$ & .07 \\
TPG (mm Hg) & $9.0 \pm 2.5$ & $8.7 \pm 2.7$ & .536 \\
\hline
\end{tabular}

$P H$, Pulmonary hypertension; $V A D$, ventricular assist device; $S P A P$, systolic pulmonary artery pressure; $D P A P$, diastolic pulmonary artery pressure; $P V R$, pulmonary vascular resistance; $T P G$, transpulmonary gradient. *Statistically significant with $P<.05$.

to $1.03 \pm 0.9, P=.003$ ) and in patients with severe $\mathrm{PH}$ (baseline $1.4 \pm 0.9$ to $0.5 \pm 0.5, P=.01)$. In addition, none of the patients in either group underwent a concomitant mitral valve repair at the time of the LVAD implant.

\section{Post-Left Ventricular Assist Device and Bridge-to- Transplant Outcomes}

In our population of 50 patients with a BTT, the survival at 6 months by Kaplan-Meier analysis (alive or transplant recipient) was $89.1 \%$. The 6-month survival (alive or transplant recipient) by Kaplan-Meier analysis in patients with severe $\mathrm{PH}$ was $88.8 \%$ compared with $93.3 \%$ in patients with non-severe $\mathrm{PH}(P=$ not significant). There was an increased incidence of right ventricular failure $(9.3 \%$ [3/32] vs $0 \%, P=.004)$ and neurologic events $(15.6 \%[5 / 32]$ vs $5.6 \%[1 / 18] P=.03)$ in the patients without severe $\mathrm{PH}$ compared with the patients with severe $\mathrm{PH}$.

The overall mean time to transplant for all 50 patients was $259 \pm 180$ days. The time to transplant in the group with severe $\mathrm{PH}$ was $280 \pm 265$ days, compared with $248 \pm 124$ days in the group without severe $\mathrm{PH}(P=$ not significant). Of the 50 patients with a BTT, $32(64 \%)$ have undergone a transplant-11 $(61 \%)$ of the 18 patients with severe $\mathrm{PH}$ and $21(65 \%)$ of the 32 patients without severe $\mathrm{PH}$ $(P=$ not significant). The 1-month posttransplant hemodynamic measurements of those 32 transplant recipients are represented in Table 4.

\section{DISCUSSION}

The discrepancy between the limited availability of donor hearts and the ever-increasing number of patients with heart failure has led to the increasing use of LVADs. ${ }^{2}$ The findings from our current study extend our and others' previous observations that continuous-flow devices, such as axial-flow LVADs, allow favorable changes in the altered pulmonary hemodynamics that are commonly seen in patients with end-stage heart failure. Previous studies have shown a lesser degree of left ventricular unloading with continuous-flow 

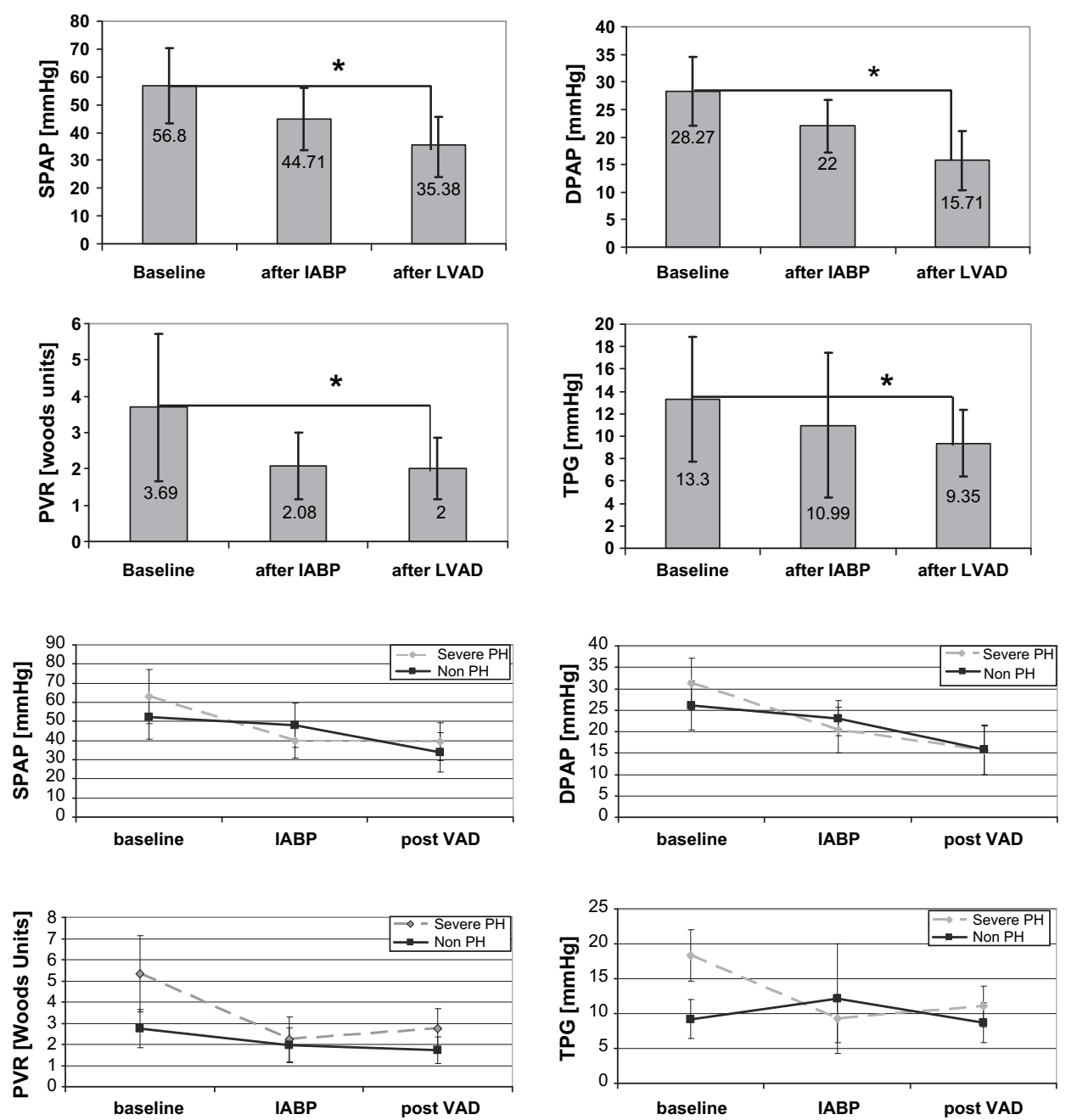

FIGURE 1. Pulmonary hemodynamics in patients with a BTT who are undergoing HeartMate II LVAD placement with $(\mathrm{n}=18)$ and without $(\mathrm{n}=32)$ severe $\mathrm{PH}(\mathrm{n}=18)$ at 2 different points: baseline (before LVAD placement) and after LVAD placement.

(vs pulsatile) devices but a similar degree of pressure unloading under resting conditions. ${ }^{8-10}$ Other end points (eg, exercise performance and cellular recovery) have also been shown to be similar for the 2 types of devices. ${ }^{11,12}$ Thus, partial unloading of the left ventricle may be sufficient to favorably influence altered pulmonary hemodynamics in patients with end-stage heart failure. Our observations confirm that the HeartMate II LVAD can be used to reverse medically unresponsive severe PH in patients with a BTT and heart failure.

Several previous studies have identified multiple risk factors for adverse heart transplant survivals, including the need for pretransplant mechanical circulatory support, $\mathrm{PH}$, a prior heart transplant, immunologic sensitization, and prolonged donor ischemic times. Outcomes after mechanical circulatory support have vastly improved, and improved immunomodulatory regimens to treat the sensitized patient are now available, yet $\mathrm{PH}$ remains a relative contraindication to a heart transplant. Certainly, improved perioperative strate- gies (including the use of intravenous phosphodiesterase inhibitors, eg, milrinone and the use of inhaled pulmonary vasodilators, eg, nitric oxide) have markedly decreased the adverse impact of $\mathrm{PH}$ on outcomes posttransplant. ${ }^{13,14}$

TABLE 4. Patient hemodynamics at 1 month posttransplant $(n=32)$

\begin{tabular}{lc}
\hline Mean follow-up, $\mathrm{d}$ & $26.5 \pm 11.1$ \\
SPAP mm Hg & $38.1 \pm 8.5$ \\
DPAP mm Hg & $16.1 \pm 4.6$ \\
Mean PAP mm Hg & $23.4 \pm 5.3$ \\
Right atrial mean mm Hg & $8.5 \pm 3.9$ \\
PCWP mm Hg & $13.8 \pm 4.9$ \\
PVR Woods Units & $1.8 \pm 0.95$ \\
TPG mm Hg & $9.8 \pm 4.4$ \\
CO L/min & $5.4 \pm 1.5$ \\
CI (fick) & $2.7 \pm 0.6$ \\
\hline
\end{tabular}

$S P A P$, Systolic pulmonary artery pressure; $D P A P$, diastolic pulmonary artery pressure; $P A P$, pulmonary artery pressure; $P C W P$, pulmonary capillary wedge pressure; $P V R$, pulmonary vascular resistance; $T P G$, transpulmonary gradient; $C O$, cardiac output; $C I$, cardiac index. 


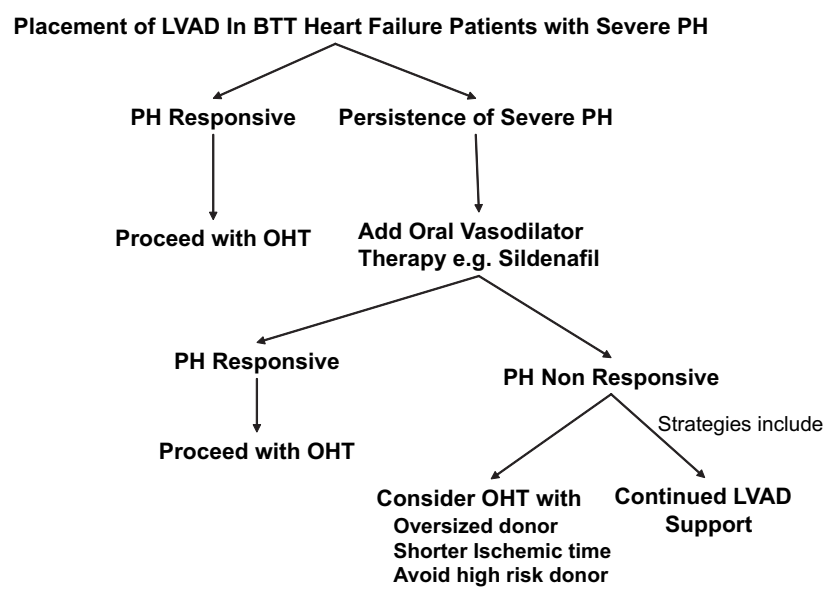

FIGURE 2. Algorithm at the University of Minnesota for the management of patients with end-stage heart failure and severe $\mathrm{PH}$ who are undergoing LVAD placement.

However, refractory or medically unresponsive $\mathrm{PH}$ is definitely associated with a higher mortality rate after a heart transplant and is therefore considered an absolute contraindication to a heart transplant. More important, some studies have identified even reversible $\mathrm{PH}$ as a risk factor for a higher mortality rate posttransplant. ${ }^{15,16}$

Discrepancies in conclusions from various studies stem from a lack of consensus on the definitions of $\mathrm{PH}$ and reversibility, as well as the various techniques used to predict reversibility. The exact degree of $\mathrm{PH}$ that confers an unfavorable prognosis is uncertain, but it remains a well-established risk factor for both early and late mortality posttransplant. ${ }^{15,16}$ Even in the case of reversible $\mathrm{PH}$, ongoing pharmacologic interventions may be insufficient to maintain the degree of PH within reasonable limits. Further, even patients with reversible $\mathrm{PH}$ face the risk of a further increase in pulmonary artery pressures after the dual insults of cardiopulmonary bypass and blood product administration. Given the adverse impact of even reversible PH on survival posttransplant, more aggressive use of LVADs as a BTT may be warranted even for patients with reversible $\mathrm{PH}$. Clearly, until now, the high morbidity and mortality rates with the larger, limited-durability pulsatile devices have limited the wider application of LVADs. But change is now likely because of recently published data supporting the improved functional status, the enhanced quality of life, and the significantly reduced adverse complications experienced with continuous-flow devices. ${ }^{17}$

As a result of this lack of definitive evidence (at least until recently), concerns have lingered about the efficacy of circulatory support (and its attendant effect on pulmonary hemodynamics) provided by continuous-flow (vs pulsatile) devices. ${ }^{18,19}$ Several series, using different types of pulsatile devices, have documented their benefits in patients with end-stage heart failure with $\mathrm{PH}$. In one of those series, Martin and colleagues ${ }^{20}$ described a patient in whom a continuous-flow Jarvik 2000 (Jarvik Heart Inc, New York, NY) was replaced with a HeartMate XVE because of inadequate pump flow. Concerns with continuous-flow devices have stemmed from their mechanism of function, namely, partial unloading (vs the more complete unloading provided by pulsatile devices). However, it was recently shown that patients with $\mathrm{PH}$ can be successfully bridged to a heart transplant with continuous-flow devices, including the MicroMed DeBakey (Micromed DeBakey, Houston, Tex) and the INCOR LVAD (BerlinHeart AG, Berlin, Germany). ${ }^{21-23} \mathrm{Etz}$ and colleagues ${ }^{21}$ reported a significant reduction in pulmonary artery pressures within 1 month after LVAD implantation in most of their patients. However, the ideal duration of LVAD support to optimize posttransplant outcomes in patients with end-stage heart failure with severe $\mathrm{PH}$ remains uncertain.

The majority of patients with mild-to moderate reversible PH undergoing heart transplantation will demonstrate significant and prompt reduction in pulmonary artery pressures. ${ }^{24}$ However, there is a group of patients with moderate-to-severe $\mathrm{PH}$ who may have persistent $\mathrm{PH}$ after a successful heart transplant; posttransplant mortality is noted to be higher in this subset of patients with $\mathrm{PH}^{25}$ It should be noted that in our study, posttransplant pulmonary hemodynamics (including PVR, TPG, SPAP, and DPAP) in the LVAD-supported patients undergoing a heart transplant remained within normal limits even in the subgroup of patients with severe $\mathrm{PH}$.

Occasionally (as seen with 4 patients in our experience), a patient with severe $\mathrm{PH}$ who is supported on an LVAD may have persistently elevated pulmonary pressures refractory to LVAD support and will require additional pulmonary vasodilator treatment. Such rare patients have no choice other than to continue on LVAD support as destination therapy, because their persistently elevated PVR makes them ineligible for a heart transplant. These patients may be removed from the transplant list, converting them to destination therapy status. However, with time and additional medical vasodilator therapy, most of these patients with refractory $\mathrm{PH}$ will demonstrate some reduction in their pulmonary artery pressures. Some patients with refractory $\mathrm{PH}$ may be considered for a heart-lung transplant or heterotopic transplant. Although both the latter 2 procedures are performed rarely in the current era, the policy at the University of Minnesota Medical Center is to strongly consider an oversized donor with a relatively shortened ischemic time for orthotopic heart transplant for these patients as opposed to a heart-lung or heterotopic transplant (Figure 2).

\section{Study Limitations}

This single-center study was limited by its relatively small number of patients. In addition, there was no randomized comparison group of patients treated with pulsatile devices 
to help us analyze the possible different impacts of the 2 types of devices on pulmonary hemodynamics. However, all of our patients underwent LVAD placement over a relatively short period of time, so their perioperative treatment protocols were consistent.

\section{CONCLUSIONS}

Continuous-flow LVAD support, when used as a BTT, effectively improves pulmonary hemodynamics in patients with end-stage heart failure. Adequate left ventricular decompression achieved with continuous-flow LVAD support, despite the partial LV unloading, can reverse significant $\mathrm{PH}$ in patients with end-stage heart failure, making them eligible for a heart transplant. Moreover, pulmonary hemodynamics remain within normal limits in the posttransplant period, even in patients with prior severe PH. This may have favorable implications for superior longer-term survival in these transplant recipients because residual posttransplant $\mathrm{PH}$ has been shown to be associated with decreased posttransplant survival. Thus, the many advantages of the smaller, continuous-flow LVADs (eg, improved durability and reliability, and reduced incidence of adverse complications) can be safely offered as a BTT to patients with heart failure and $\mathrm{PH}$.

The authors thank Mary E. Knatterud, $\mathrm{PhD}$, for editorial assistance.

\section{References}

1. Taylor DO, Edwards LB, Aurora P, Christie JD, Dobbels F, Kirk R, et al. Registry of the International Society for Heart and Lung Transplantation: twenty-fifth official adult heart transplant report-2008. J Heart Lung Transplant. 2008;27: 943-56.

2. Frazier OH, Rose EA, McCarthy P, Burton NA, Tector A, Levin H, et al. Improved mortality and rehabilitation of transplant candidates treated with a long-term implantable left ventricular assist system. Ann Surg. 1995;222: 327-36.

3. Griffith BP, Kormos RL, Borovetz HS, Litwak K, Antaki JF, Poirier VL, et al. HeartMate II left ventricular assist system: from concept to first clinical use. Ann Thorac Surg. 2001;71:116-20.

4. John R, Kamdar F, Liao K, Colvin-Adams M, Boyle A, Joyce L. Improved survival and decreasing incidence of adverse events using the HeartMate II left ventricular assist device as a bridge-to-transplant. Ann Thorac Surg. 2008;86: 1227-35.

5. John R, Rajasinghe H, Chen JM, Weinberg AD, Sinha P, Itescu S, et al. Impact of current management practices on early and late death in more than 500 consecutive cardiac transplant recipients. Ann Surg. 2000;232:302-11.

6. Costard-Jackle A, Hill I, Schroeder JS, Fowler MB. The influence of preoperative patient characteristics on early and late survival following cardiac transplantation. Circulation. 1991;84:III329-37.

7. Chen JM, Levin HR, Michler RE, Prusmack CJ, Rose EA, Aaronson KD. Reevaluating the significance of pulmonary hypertension before cardiac transplantation: determination of optimal thresholds and quantification of the effect of reversibility on perioperative mortality. J Thorac Cardiovas Surg. 1997;114:627-34.

8. Haft J, Armstrong W, Dyke DB, Aaronson KD, Koelling TM, Farrar DJ, et al. Hemodynamic and exercise performance with pulsatile and continuous-flow left ventricular assist devices. Circulation. 2007;116:I8-15.

9. Klotz S, Deng MC, Stymann J, Roetker J, Wilhelm MJ, Hammel D, et al. Left ventricular pressure and volume unloading during pulsatile versus nonpulsatile left ventricular assist device support. Ann Thorac Surg. 2004;77:143-50.

10. Garcia S, Kamdar F, Boyle A, Colvin-Adams M, Liao K, Joyce L, et al. Effects of pulsatile- and continuous-flow left ventricular assist devices on left ventricular unloading. J Heart Lung Transplant. 2008;27:261-7.

11. Thohan V, Stetson SJ, Nagueh SF, Rivas-Gotz C, Koerner MM, Lafuente JA, et al. Cellular and hemodynamic responses of failing myocardium to continuous flow mechanical circulatory support using the DeBakey-Noon left ventricular assist device: a comparative analysis with pulsatile-type devices. J Heart Lung Transplant. 2005;24:566-75.

12. Barbone A, Holmes JW, Heerdt PM. Comparison of right and left ventricular responses to left ventricular assist device support in patients with severe heart failure. A primary role of mechanical unloading underlying reverse remodeling. Circulation. 2001;104:670-5.

13. Pamboukian SV, Carere RG, Webb JG, Cook RC, D'yachkova Y, Abel JG, et al. The use of milrinone in pre-transplant assessment of patients with congestive heart failure and pulmonary hypertension. J Heart Lung Transplant. 1999;18:367-71.

14. Argenziano M, Choudhri AF, Moazami N, Rose EA, Smith CR, Levin HR, et al. Randomized, double-blind trial of inhaled nitric oxide in LVAD recipients with pulmonary hypertension. Ann Thorac Surg. 1998;65:340-5.

15. Butler J, Stankewicz MA, Wu J, Chomsky DB, Howser RL, Khadim G, et al. Pretransplant reversible pulmonary hypertension predicts higher risk for mortality after cardiac transplantation. J Heart Lung Transplant. 2005;24:170-7.

16. Klotz S, Wenzelburger F, Stypmann J, Welp H, Drees G, Schmid C, et al. Reversible pulmonary hypertension in heart transplant candidates: to transplant or not to transplant. Ann Thorac Surg. 2006;82:1770-3.

17. Miller LW, Pagani FD, Russell SD, John R, Boyle AJ, Aaronson KD, et al. Use of a continuous-flow device in patients awaiting heart transplantation. $N$ Engl J Med. 2007;357:885-96.

18. Feller ED, Sorensen EN, Haddad M, Pierson RN, Johnson FL, Brown JM, et al. Clinical outcomes are similar in pulsatile and nonpulsatile left ventricular assist device recipients. Ann Thorac Surg. 2007;83:1082-8.

19. Klotz S, Stypmann J, Welp H, Schmid C, Drees G, Rukosujew A, et al. Does continuous flow left ventricular assist device technology have a positive impact on outcome pretransplant and posttransplant? Ann Thorac Surg. 2006;82:1774-8.

20. Martin J, Siegenthaler MP, Friesewinkel O, Fader T, van de Loo A, Trummer G, et al. Implantable left ventricular assist device for treatment of pulmonary hypertension in candidates for orthotopic heart transplantation - a preliminary study. Eur J Cardiothorac Surg. 2004;25:971-7.

21. Etz CD, Welp HA, Tjan TD, Hoffmeier A, Weigang E, Scheld HH, et al. Medically refractory pulmonary hypertension: treatment with nonpulsatile left ventricular assist devices. Ann Thorac Surg. 2007;83:1697-706.

22. Salzberg SP, Lachat ML, von Harbou K, Zund G, Turina MI. Normalization of high pulmonary vascular resistance with LVAD support in heart transplantation candidates. Eur J Cardiothorac Surg. 2005;27:222-5.

23. Zimpfer D, Zrunek P, Roethy W, Czerny M, Schima H, Huber L, et al. Left ventricular assist devices decrease fixed pulmonary hypertension in cardiac transplant candidates. J Thorac Cardiovasc Surg. 2007;133:689-95.

24. Lindelow B, Andersson B, Waagstein F, Bergh CH. High and low pulmonary vascular resistance in heart transplant candidates. A 5-year follow up after heart transplantation shows continuous reduction in resistance and no difference in complication rate. Eur Heart J. 1999;20:148-56.

25. Goland S, Czer LSC, Kass RM, De Robertis MA, Mirocha J, Coleman B, et al. Pre-existing pulmonary hypertension in patients with end-stage heart failure: Impact on clinical outcome and hemodynamic follow-up after orthotopic heart transplantation. J Heart Lung Transplant. 2007;26:312-8. 